\title{
Histórias vívidas: usos do passado recente entre jovens estudantes
}

Vivid History: Uses of the Recent Past among Young Students

Juliana Pirola da Conceição Balestra*

\begin{abstract}
Resumo
$\mathrm{O}$ artigo apresenta os resultados de uma pesquisa acerca da construção de memórias sobre as Ditaduras em duas das cidades mais afetadas pela repressão na América Latina: São Paulo e Buenos Aires. A pesquisa foi realizada em 2013 e contou com a participação de 101 jovens estudantes que cursavam o último ano da escolarização obrigatória do seu país em escolas públicas de ambas as cidades. Os jovens que participaram da pesquisa não viveram diretamente esse passado, mas lhe conferem diferentes sentidos na tomada de decisões no presente, revelando como as políticas públicas de memória são incorporadas nos espaços educativos, como parte de uma consciência histórica. Palavras-chave: ditadura; ensino de história; América Latina.
\end{abstract}

\begin{abstract}
This article presents the results of a research on memories of the dictatorships in two cities amongst the most affected by repression in Latin America: São Paulo and Buenos Aires. The research was conducted in 2013. In total, 116 young students have participated in the research. In both cities they were attending the last year of compulsory schooling in public schools. They did not live the repression directly, but they relate the past to make decisions in present, revealing how the public policies of memory are incorporated in educational places, as part of a historical consciousness.

Keywords: dictatorship; History teaching; Latin America.
\end{abstract}

O grau de liberdade com o qual atuamos no processo histórico é diretamente proporcional à consciência que tivermos do passado que nos constitui e condiciona.

Cerri, 2003

Entre os temas mais sensíveis da história recente da América Latina estão as Ditaduras de Segurança Nacional, grande parte delas protagonizada por

\footnotetext{
* Universidade Federal da Integração Latino-Americana (Unila). Foz do Iguaçu, PR, Brasil. juliana.balestra@unila.edu.br
} 
militares, conhecidos pelos crimes cometidos contra a humanidade na violação de direitos humanos. Época em que o Estado, que deveria zelar pela proteção dos seus cidadãos, era justamente quem os atacava (Bauer, 2011).

Nas décadas de 1960 e 1970, países como Paraguai, Brasil, Bolívia, Argentina, Chile e Uruguai experimentaram variações do regime na luta contra seus inimigos internos, que questionavam e criticavam o sistema estabelecido subversivamente, pondo em risco a segurança nacional, mesmo que para isso fosse necessário agir contra a lei. ${ }^{1}$ A partir do estabelecimento de alianças estratégicas com os Estados Unidos, muitos desses regimes justificaram a violência implantada na luta contra o comunismo, associada não só aos movimentos anticapitalistas, mas também a todas as expressões dos dissensos sociais, como sindicatos, partidos políticos, movimentos sociais, universidades, meios de comunicação, artistas e intelectuais. Como característica comum, eles impuseram a militarização do Estado, com as Forças Armadas assumindo o papel de dirigentes políticos e agentes da repressão, e mantiveram-se no poder por meio de violenta repressão contra movimentos de oposição e resistência (Sader et al., 2006, p.412).

Para coordenar as atividades repressivas na região, esses regimes se uniram em um pacto internacional clandestino: a "Operação Condor”, ultrapassando as fronteiras nacionais. A operação funcionou como um sistema de intercâmbio de informações e contou com a colaboração da Venezuela, do Peru, da Colômbia, do Equador e dos Estados Unidos, mas logo se converteu em uma agência internacional que prendia, torturava e assassinava a qualquer pessoa que parecesse subversiva ou perigosa.

Meio século depois dos fatos ocorridos, esse passado permanece latente por sua carga singular de dor e violência, e sua assimilação apresenta uma dificuldade especial. Um passado que não passa. Nas palavras de Marina Franco e Florencia Levín (2007), uma "historia reciente", assim como os grandes genocídios do século XX, que ainda ativam lutas no presente e projetos de futuro. Histórias vívidas que resistem em se converter em histórias vividas, não só pelas disputas por sua significação, mas também pela sua perpetuação: crimes ainda não foram julgados, jovens apropriados permanecem com sua identidade adulterada, milhares de corpos não foram sepultados, muitos amigos e familiares seguem na busca por informações sobre seus entes "desaparecidos", 
e pactos de silêncio impedem o acionamento da justiça e a construção de memórias sobre o período (Bauer, 2011).

Vera Carnovale e Alina Larramendy (2010), referindo-se ao caso argentino, mas sem se restringir a ele, destacam que os relatos formadores de memória que circulam no espaço social desde a última ditadura até a atualidade reconhecem valorações políticas e ideológicas diversas, quando não excludentes. Segundo as autoras, desde o início dos regimes ditatoriais se reivindicou a memória sobre o papel primordial das Forças Armadas na guerra contra a subversão e o terrorismo para salvaguardar o mundo ocidental cristão, ameaçado pelas forças do marxismo internacional. Essa memória postula que, como em toda guerra, houve consequências tanto dolorosas quanto inevitáveis, que deveriam ficar sujeitas apenas ao juízo de Deus em cada consciência.

Outra memória está associada à chamada "teoria dos dois demônios", que condena tanto o papel das Forças Armadas como o das organizações guerrilheiras. Recorrendo a certas representações coletivas sobre a violência política e a repressão, elas oferecem uma imagem de dois tipos equivalentes de terrorismo: o de extrema direita e o de extrema esquerda. Essa memória tem sido sistematicamente combatida pelos movimentos de direitos humanos e pelos setores vinculados à militância política revolucionária da década de 1970. Em primeiro lugar, porque iguala em termos de responsabilidade as ações de alguns grupos políticos e organizações armadas com o aparato repressivo ilegal do Estado. Em segundo lugar, porque oferece a imagem de uma sociedade, ou de uma maioria, supostamente alheia e ausente das lutas políticas e sem nenhum tipo de responsabilidade na instalação e sustentação do terror pelo Estado (Carnovale; Larramendy, 2010).

De outro ponto de vista, claramente condenatório do papel do Estado, sobressai uma memória centrada na figura da "vítima inocente" da repressão. Um aspecto central dessa memória é o silêncio em torno da militância política das pessoas detidas/desaparecidas ou a sua participação em movimentos de luta armada. Quando, eventualmente, se faz menção à sua militância, são enfatizadas as ações de solidariedade social, como a alfabetização e a ajuda em bairros pobres no combate à miséria, e se omite o fato de que essas mesmas ações estavam relacionadas às atividades políticas de organizações armadas ou de agrupamentos que respondiam a elas (Carnovale; Larramendy, 2010). 
Por fim, apresentam-se as memórias militantes, nas quais os testemunhos e balanços de antigos militantes ocupam lugar central. Essas não formam um conjunto homogêneo de relatos, mas agregam distintas valorações das experiências de militância. Existem vozes que reivindicam a totalidade dessa experiência, tanto os motivos que impulsionaram boa parte de uma geração a abraçar a causa revolucionária, quanto a atuação das organizações armadas em si. Outras ainda reivindicam os objetivos daquela causa sob um olhar retrospectivo, advertindo sobre certos erros. E existem também aquelas que, por diversos motivos, se distanciam da experiência vivida, seja porque deixaram de compartilhar seus fundamentos, seja porque hoje duvidam de suas implicações éticas (Carnovale; Larramendy, 2010).

Enquanto o jogo entre memória e esquecimento permanece em conflito, esse passado aberto, ainda inconcluso, segue disposto a ser modelado pelas experiências do presente. No Brasil, a data que lembrou o cinquentenário do golpe, o dia 31 de março de 2014, foi marcada por ambiguidades. Enquanto organizações populares, ex-presos políticos e familiares de mortos e desaparecidos fizeram uma série de atos públicos de "(des)comemoração", pessoas insatisfeitas com o governo se reuniram na principal avenida de São Paulo, a Avenida Paulista, para festejar os 50 anos da chamada "Revolução Redentora". ${ }^{2}$ Em 2015, mais do que comemorar a "Revolução de 64 ", centenas de pessoas pediram a "volta" da ditadura "pela restauração da ordem em um país onde a inversão de valores é vergonhosa e a censura e o politicamente correto imperam com base na hipocrisia". ${ }^{3}$ Como lembrou Caroline da Silveira Bauer (2015), paradoxalmente, a data escolhida para as manifestações - 15 de março - marcava os exatos 30 anos de retorno à democracia, caso se considere o ano de 1985 e a posse de José Sarney como marcos democráticos do no processo de transição política. À época, muitos responderam: "Faltam aulas de História! Estão banalizando o nosso processo democrático, porque não se estuda a ditadura nas escolas", reconhecendo que muitos dos chamados "saudosistas" não vivenciaram a ditadura e, portanto, não poderiam reivindicar a "volta" do que nunca experimentaram.

\section{O QUE FICA DESSA HISTÓRIA?}

Como "lembrar" aqueles fatos que não foram diretamente experimentados? Como "lembrar" o que não se viveu? Para Beatriz Sarlo (2007), as aspas 
demarcam o deslocamento entre lembrar o vivido e lembrar as representações alheias, que podem compor o nosso acervo memorialístico a partir de um investimento familiar, político e, sobretudo, escolar.

No entanto, a abordagem recorrente no ensino de história persistiu muito tempo com a ideia de que não cabe à História ou ao seu ensino tomar partido nas disputas sobre a construção de memórias, e, com isso, perpetua-se a estratégia de não estudar a história "mais recente". O principal argumento é que essa história ainda não foi escrita e, portanto, não pode ser ensinada. Além disso, ela poderia gerar certos constrangimentos, porque muitos dos principais protagonistas desse passado ainda estão vivos e ativos na arena político-social. Com isso, o ensino de história tem se afastado das polêmicas e focado em temas consagrados, mas quando pessoas que não viveram esses regimes se reúnem em manifestações para pedir a "volta" da ditadura, o reflexo do descaso começa a assustar.

Passados mais de 30 anos dos acontecimentos que puseram fim aos regimes ditatoriais na região, o que fica dessa história? Como nos relacionamos com ela? Qual o seu peso em nossas vidas e nas decisões que tomamos? No intuito de investigar as relações entre as políticas públicas de memória e os usos desse passado recente na tomada de decisões entre os jovens que não viveram o período, visitaram-se quatro escolas públicas de duas das cidades mais afetadas pela repressão na América Latina - São Paulo e Buenos Aires -, escolas onde diariamente os portões se cruzam duplamente: pela objetividade do ensino e pelo dever de memória. Ambas as cidades passaram por experiências semelhantes em um mesmo período - as Ditaduras de Segurança Nacional, o terrorismo de Estado e a prática do desaparecimento -, mas possuem práticas distintas para lembrar, reparar ou esquecer esse passado, como parte de uma consciência histórica que orienta a tomada de decisões no presente. ${ }^{4}$

Os jovens que participaram da pesquisa não viveram diretamente esse passado, e, para entender como essa história chega a eles, suas representações e as atitudes que mobiliza, é preciso considerar as relações entre História e Ensino de História no desenvolvimento de políticas públicas para o ensino promovido pelas escolas. Além disso, sabe-se que não se aprende história só na escola, sendo cada vez mais importante o papel dos meios de comunicação, dos espaços de memória e dos laços afetivos na abordagem do período. 
A pesquisa foi realizada em 2013 e envolveu o questionamento sobre a decisão a ser tomada em uma situação hipotética, ${ }^{5}$ que envolvia o pedido de ajuda de um "vizinho estrangeiro" procurado pela polícia por divulgar na internet documentos considerados sigilosos sobre seu país de origem. Na proposição, sinalizou-se que esse "vizinho" vinha de um país também "vizinho", donde se poderia concluir que se tratava de um imigrante latino-americano. Além disso, optou-se por contextualizar a questão apresentando um texto sobre a "Operação Condor", para estimular o estabelecimento de relações entre a situação proposta e a história recente da região.

A ideia de "vizinho" tinha como objetivo fomentar relações de proximidade e facilitar o estabelecimento de empatia com a situação vivenciada. Ser "vizinho", nesse caso, poderia representar não só morar perto, mas também pertencer ao mesmo grupo, relacionar-se, conviver, compartilhar um espaço e também uma história. Entretanto, faz-se necessário esclarecer que não existia de antemão uma "narrativa desejada". A intenção era investigar justamente se e como jovens que não vivenciaram diretamente um passado usam a história para analisar uma situação presente e determinar cursos de ação, conferindo-lhe historicidade.

As respostas elaboradas, compreendidas como narrativas históricas, foram analisadas em função das relações estabelecidas entre passado, presente e futuro para dar plausibilidade às decisões tomadas, seja para explicá-las ou justificá-las, conferindo-lhes historicidade.

Nas décadas de 1970 e 1980 os governos militares da América Latina realizaram um esforço sem precedentes para coordenar suas atividades repressivas em toda a região. As ditaduras se uniram e ultrapassaram as fronteiras entre os países, dando origem a um dos piores exemplos de terrorismo de Estado na história. O acordo foi batizado com um nome imponente e simbólico: "Operação Condor", referindo-se à maior ave de rapina das Américas, conhecida por se alimentar de carniça, como os urubus.

A operação funcionou como um pacto internacional clandestino entre cinco ditaduras da região: Argentina, Chile, Paraguai, Uruguai e Bolívia, contando com a colaboração da Venezuela, do Peru, da Colômbia, do Equador e também dos Estados Unidos. Ela foi projetada como um sistema de intercâmbio de informações sobre conhecidos simpatizantes comunistas em todo o continente, mas logo se 
converteu em uma agência internacional do terror, que prendia, torturava e assassinava qualquer pessoa que parecesse subversiva ou perigosa.

A colaboração entre as ditaduras começou com o exílio de centenas de pessoas que buscaram refúgio e asilo político em outros países da região e até mesmo na Europa e nos Estados Unidos. Temendo que essas pessoas pudessem organizar formas de resistência e fazer denúncias a partir de outros países, as ditaduras se uniram. Assim, qualquer pessoa considerada subversiva podia ser perseguida e assassinada onde quer que estivesse.

A Operação estava dividida em duas fases principais: a primeira visava uma troca sistemática de informações entre os serviços secretos de cada país sobre as pessoas consideradas subversivas. Essas informações eram obtidas por meio de espionagem para construção do banco de dados comum a todos os países membros do acordo. A segunda fase visava prender e deportar os presos políticos para seus países de origem, mas muitos terminaram sendo executados nos países onde foram encontrados.

Entre os casos mais conhecidos da Operação estão o assassinato do general chileno Carlos Prats, na Argentina, o assassinato do ex-ministro do governo de Salvador Allende, Orlando Letelier, nos Estados Unidos, e a tentativa de sequestro no Brasil do casal de militantes políticos uruguaios, Universindo Rodríguez Díaz e Lilian Celiberti.

Agora imagine que entre os moradores do prédio onde você mora vive um estrangeiro de um país vizinho, que se mudou recentemente. Comentam no prédio que ele corre o risco de ser preso e deportado por divulgar na internet documentos considerados sigilosos do seu país de origem. Em uma noite escura ele bate à sua porta pedindo ajuda e conta que está sendo perseguido pela polícia.

O que você faria? O ajudaria a esconder-se ou tomaria outra atitude?

É necessário explicar a um amigo o que está acontecendo, mas ele não conhece a história.

Como você contaria a ele toda a história, a situação em que você se encontra e a decisão que pretende tomar?

Para ajudá-lo a entender sua decisão, você pode estabelecer relações com outros acontecimentos históricos e acrescentar informações. Justifique a sua resposta. 
No total, 101 jovens estudantes participaram da pesquisa, sendo 60 de São Paulo e 41 de Buenos Aires. ${ }^{6}$ A maioria tinha entre 15 e 17 anos. Em São Paulo, eles cursavam o $3^{\circ}$ ano do Ensino Médio; em Buenos Aires, o $5^{\circ}$ ano da "Escuela Media". Em ambas as cidades priorizou-se o último ano da escolarização básica para investigar como os jovens saem da escola ao final de um longo processo de escolarização.

Nas respostas elaboradas, o número de jovens que usou a história das ditaduras para tomar sua decisão foi maior em Buenos Aires: 15 de 41 (36,5\% do total); enquanto em São Paulo foram apenas 6 de 60 (10\% do total). Nessas narrativas, foram feitas referências às últimas ditaduras em seus próprios países e também nos demais países da região, como mostram estes exemplos:

Venha, entre. Te ajudarei

Sem dúvidas, o 'preso político' seria ajudado por mim. Os fatos ocorridos na ditadura militar me fariam pensar que aquele seria um passado não distante, onde a opressão ainda permanece contra aqueles que se opõem as ideias, muitas vezes corruptas do governo. Prendiam e torturavam protestantes, que não aceitasse.

Hoje vivemos em um país que se diz democrático, mas certos modos para reprimir a população ainda está presente.

(Estudante de São Paulo)

Si lo ayudaría porque en otros momentos de la historia como durante la última dictadura militar muchos militantes políticos teneron que exilarse porque eran perseguidos por los gobiernos de Latinoamérica y creo que aún en la actualidad los gobiernos de la región continúan con acciones de tiempos no democráticos. Por lo que si lo estoy persiguiendo le debería ayudarlo.

(Estudante de Buenos Aires)

Yo lo ayudaría ya que en años atrás se vivó una dictadura y un autoritarismo en muchos países.

Muchas familias huian de su pais de origen y se ivan a otros países por lo tanto yo lo ayudaría así salvaría a una vida.

Despues hablaria con el y le preguntaría por que lo persigue la policia. 
Hablaria con un amigo y le contaria por la situación en la que me encuentro.

Le diría:

Amigo en mi casa llego un hombre tocandome la puerta, estaba muy desesperado pidiéndome auxilio, ya que lo perseguia la policia. Lo vi tan mal y me hizo acordar tanto a nuestra historia que decidí ayudarlo.

Los policías y los gobiernos son muy injustos ya que si no estan de acuerdo con sus reglas quieren matar a las personas.

Cada dia muere tantos inocentes, tantos niños, tantas personas que no deberian haber muerto.

Realmente es un dolor grande todo lo que se ha vivido en nuestra historia y ese hombre esta viviendo en carla propia esas injusticias y prefiero ayudarlo (salvar una vida) que dejar que lo maten, ya que para la policia es un numero más. Una persona que hay que matar y ya! Los gobiernos autoritarios no tienen ese valor a la vida y yo no quisiera contribuir con eso, la vida es muy importante y hay que valorarla!

Todos tenemos pensamientos diferentes o formas de pensar distintos por lo tanto un gobierno autoritario no nos pueden venir a callar, tenemos que ser voces fuertes!

Y no hay que llevar las causas a la violencia sino al dialogo.

(Estudante de Buenos Aires)

Nas respostas em que a perspectiva histórica não apareceu, o componente moral sobressaiu como elemento legitimador das decisões tomadas.

Não ajudaria pois não é problema meu. Se a polícia está atrás algo errado ele fez.

(Estudante de São Paulo)

Independente do que ele fez sim eu ajudaria, mais só se ele me desse um valor bem alto em dinheiro. eu esconderia ele em algum lugar distante da minha casa. e voltaria a minha rotina de vida com o meu bolso cheio de dinheiro.

(Estudante de São Paulo) 
Si fuera un vecino con el que tenga buena relación, lo ayudaría a esconderse simplemente porque no me interesarían una mierda los "documentos confidenciales" y estaría haciendole un favor a un amigo o conocido. En resumen, no me importaría lo que esté haciendo, solo tomaria mi decisión basandome en la relación que tuviera con el individuo.

(Estudante de Buenos Aires)

A maioria das respostas sugere que as decisões são tomadas com base apenas na situação vivida no presente, sem a construção de perspectivas históricas de raciocínio. Em alguns casos, consideram-se apenas as relações entre presente e futuro. Isso remete às conexões que se deslocam da interface entre memória e história para a inter-relação entre memória e expectativa - "entre o passado conhecido e o futuro desejado", como aponta Jörn Rüsen (2014). Segundo esse autor, a história, como narrativa, serve para dar sentido à passagem do tempo e funciona como um meio de orientação e coerência nos afazeres do cotidiano, como uma consciência histórica. Para preencher essa função, o pensamento histórico precisa seguir uma lógica específica, observada em três planos (Rüsen, 2009, p.168-169):

1) O da percepção da mudança temporal - percepção das diferenças entre passado e presente.

2) O da interpretação - relação entre passado e presente para dar sentido ao presente.

3) O da orientação da vida prática - tomada de decisões.

Como a maioria dos jovens sequer usou o passado para tomar sua decisão ou para justificá-la, talvez fosse possível concluir que a percepção da diferença temporal foi generalizada, que o presente foi concebido como tão distante do passado que nem foi possível estabelecer qualquer relação com ele. No entanto, o que se observa é a negação das relações entre passado e presente, levando a supor, como aponta Reinhart Koselleck (2006), que o passado não serve como exemplo, dado o seu caráter irrepetível, e vive-se apenas para o futuro. Em outros casos, a ênfase no presente o torna seu próprio horizonte, promovendo um afastamento não só da experiência, mas também da expectativa, e com isso o passado perde a sua capacidade de orientar o presente. 
Acredita-se que a ausência dessa perspectiva temporal na tomada de decisões esteja relacionada tanto ao desconhecimento do período histórico abordado quanto à falta de prática de se recorrer ao passado para pensar sobre o presente, dada a ênfase no caráter objetivo e informativo do ensino de história nas escolas e nos meios de comunicação em geral.

Nas respostas em que o passado foi utilizado como elemento orientador das decisões observa-se a predominância de interpretações que pressupõem a repetição da história em um contínuo que fornece lições para o presente. Entre elas, destacam-se os seguintes trechos:

Eu tomaria a decisão de abrigá-lo, pois estudando história, conheci várias histórias de perseguição de governos políticos, e sei que ele vai sofrer muito.

(Estudante de São Paulo)

Si lo ayudaría porque en otros momentos de la historia como durante la última dictadura militar muchos militantes políticos teneron que exilarse porque eran perseguidos por los gobiernos de Latinoamérica y creo que aún en la actualidad los gobiernos de la región continúan con acciones de tiempos no democráticos.

(Estudante de Buenos Aires)

Viene a mi mente la dictadura de nuestro país en la década del 70, el golpe de Estado de 1976, que duró más de tres años, arrestaban y torturaban a muchas personas, hubo más de 1000 desaparecidos, es una historia triste de lo argentino de la cual no quiero ser parte así que ayudé al hombre, lo escondí para que no lo encontraran y si algún día me condenaran por tal cosa, me alegraré de no haber sido parte de un masacre más.

(Estudante de Buenos Aires)

Nessas narrativas, é possível observar certa "predisposição ao sacrifício" e a permanência de regras gerais de conduta, como uma moral estabelecida em relação aos perseguidos políticos na região. A história é vista como uma recordação do passado, a perseguição política e a violência policial/militar seguem se repetindo e não se questiona o asilo a um "perseguido político". Com isso, as relações entre situações particulares e suas regularidades servem tanto ao 
passado quanto ao futuro. O problema é que, seguindo essa lógica, a moral assume uma validade atemporal e universal e os valores atribuídos ao passado seguem determinando o presente de modo inquestionável. Em outros casos, ela advém de experiências familiares anteriores, como nestes trechos:

Olha mãe, ele divulgou uns arquivos na internet, sigilosos, e descobriram. Como ele precisava de ajuda, bateu aqui na porta, pedindo-a. Eu acredito que se ele confiou em mim para contar essa história, eu precisava ajudá-lo. Então, peguei a fantasia do pai do ano passado, de detetive e falei para ele fugir, dei o dinheiro e o endereço de um amigo que mora no interior de São Paulo. Eu sei que o que fiz é meio que um crime, mas o vô ficaria tão feliz em poder ajudar, porque foi assim que ele conseguiu sobreviver as torturas que passou na época da ditadura. Então ajudei sim, pensando no vô e no pobre do homem que tava morrendo de medo.

(Estudante de São Paulo)

Em outras respostas observa-se, ao contrário, que a ruptura da continuidade temporal se dá exatamente pela negação de sua validade e pela crítica aos valores atemporais, que já não servem para orientar o presente:

La decisión que tomaria es no ayudarlo porque ya no puedo ayudar a una persona que no conozco y tampoco puedo creer lo que escuche por los vecinos sea sierto o no. No puedo tener mucha confianza.

Por más que sé que en mi pais ubo una dictadura, que mataban a las persona, detenían o secuestraban y que hobo muchos desaparecidos en ese 'golpe de Estado'.

(Estudante de Buenos Aires)

Tais narrativas expressam a oportunidade de romper com papéis e formas prescritas e desafiar valores morais preestabelecidos. O argumento crítico é que, mesmo havendo passado por ditaduras, não se sente a "obrigação" de dar asilo a um perseguido político desconhecido e, com isso, a história perde sua inevitabilidade.

Em outra resposta, que destoa das demais analisadas, é possível observar que a percepção da mudança temporal se converte justamente no elemento 
que dá sentido à história e com isso a decisão tomada difere, necessariamente, do que teria sido em outra época.

Es una situación bastante inusual, si fuera una época como la dictadura quizás lo ayudaría, si lo quieren matar o torturar, seguro lo ayudaría, si solo lo quieren aprisionar, no me involucraría.

(Estudante de Buenos Aires)

Nessa narrativa, o argumento principal é que “os tempos mudam”, e a obrigação em relação aos acontecimentos passados também. Com isso, permite-se que a história faça parte do passado e lhe é conferido outro futuro, despojado de seu caráter universal. De acordo com Rüsen (2009), esse tipo de interpretação histórica, também conhecido como consciência histórica genéti$c a$, é a forma mais refinada do pensamento histórico moderno, no qual o futuro supera o passado em seu direito sobre o presente. A partir daí, diferentes pontos de vista podem ser aceitos porque se integram em uma perspectiva abrangente de mudança temporal. Essa é a relação de sentido que se deveria esperar como resultado de um processo de aprendizagem histórica, seja na escola ou fora dela, mas parece que ainda existe um longo caminho a se percorrer até que ela seja generalizada, mesmo na Argentina.

Um ponto importante é que em nenhum dos casos em que a história das ditaduras foi usada para orientar a tomada de decisões optou-se por entregar o "vizinho" à polícia, ainda que tenham optado por não ajudá-lo. Para a maioria dos jovens que demonstraram usar nossa história recente para tomar uma decisão, ela promoveu a construção de identidades, de empatia, e levou à mobilização de atitudes solidárias.

Não é possível afirmar que as decisões tomadas na resolução de um problema hipotético poderiam se repetir em situações reais ou que, se o contexto utilizado fosse outro, a frequência no uso do passado para tomar uma decisão no presente seria a mesma. $\mathrm{O}$ que as narrativas analisadas oferecem são indícios de intenções, de disposições para o agir, construídas a partir da reflexão sobre o uso que se pode fazer no presente desse passado, tão próximo e tão violento. E, neste caso, para que nossa história não se limite a reproduzir o passado e lhe conceda um novo futuro, é preciso construir novos horizontes de interpretação e convertê-los em princípio de ação das práticas cotidianas. 


\section{O PAPEL DA EDUCAÇÃO E DO ENSINO DE HISTÓRIA}

O objetivo da questão proposta não era revelar o que os jovens sabem, como conteúdo, da história das ditaduras, mas investigar como se posicionam diante dela e os sentidos que lhe conferem na tomada de decisões no presente. Para entender o papel da escola nesse processo, buscaram-se nos documentos que orientam o ensino de história em cada cidade, desde o fim dos regimes ditatoriais até a atualidade, indícios dos conteúdos e das abordagens presentes ao longo da formação escolar desses jovens que permitissem relacioná-las com as narrativas elaboradas. São diretrizes curriculares, leis educacionais, materiais didáticos e projetos educativos que se configuram, em última instância, como políticas públicas de memória para determinar o que deve ser lembrado e o que deve ser esquecido sobre esse passado.

Da cidade de São Paulo, foram analisadas a Proposta Curricular de 1992, a Proposta Curricular de 2007/2012, os Cadernos de São Paulo, duas das coleções de livros didáticos que mais circulam na cidade e os projetos educativos para o trabalho com o período. De Buenos Aires, foram analisados o Diseño Curricular para la Educación Primaria Común/1986, o Diseño Curricular para la Escuela Primaria/2004, os Contenidos para el Nivel Medio/2009, os Aportes para el desarrollo curricular/2010 e também duas das coleções de livros didáticos que mais circulam na cidade e demais projetos educativos sobre a temática. Além disso, foi necessário considerar também a dimensão nacional dessas políticas curriculares e contextualizá-las com iniciativas que lutam para impedir que essa história caia no esquecimento. ${ }^{7}$

Em São Paulo, a história das ditaduras aparece como proposta para o ensino dos últimos bimestres da $8^{\mathrm{a}}$ série $/ 9^{\circ}$ ano do Ensino Fundamental e do $3^{\circ}$ ano do Ensino Médio. A abordagem predominante prioriza a história nacional, com ênfase nos aspectos políticos e econômicos, nas medidas tomadas pelos diferentes presidentes e nas mudanças promovidas pelos Atos Institucionais. Os movimentos de resistência e a luta armada são apresentados superficialmente, e o estabelecimento de relações com outros países se resume à citação dos nomes dos países que também passaram por ditaduras no mesmo período. As Forças Armadas aparecem homogeneizadas na categoria de "militares" como o principal ator social do período, e a participação da sociedade civil é destacada apenas no processo de redemocratização. A terminologia 
frequentemente utilizada é "regime militar pós-64", que não caracteriza nem se posiciona criticamente em relação ao período, e também não discute a participação dos civis no processo, assim como "ditadura militar"/"golpe militar", e não "civil-militar". As discussões propostas não são relacionadas ao presente, e o silenciamento sobre o processo de anistia ao final do regime pode dificultar o entendimento das demandas atuais por reparação e justiça.

Em âmbito nacional, no Brasil não existe nenhuma política educacional explícita para a abordagem da temática, que apenas figura como um conteúdo a mais a ser estudado entre os tantos outros propostos pelos Parâmetros Curriculares Nacionais (PCN). Ninguém foi punido pelos crimes cometidos durante o regime, e o acesso à documentação militar começou a ser permitido apenas em 2012, com a instalação da Comissão Nacional da Verdade (CNV), mas ainda cabe aos familiares das vítimas do regime o ônus de provar a responsabilidade do Estado nas mortes e nos desaparecimentos (Bauer, 2011).

Os lugares de memória do período também não foram demarcados por políticas públicas, mas por iniciativas pontuais. ${ }^{8}$ A exceção é o Memorial da Resistência de São Paulo, um museu público que ocupa o edifício que abrigou a sede do antigo Departamento Estadual de Ordem Política e Social de São Paulo (Deops/SP). O Memorial é uma iniciativa do Fórum Permanente de ex-Presos e Perseguidos Políticos do Estado de São Paulo e do Governo do Estado de São Paulo, que desde 2009 consolidou o espaço como uma instituição dedicada à preservação das memórias da resistência e da repressão políticas do Brasil. Além de programa museológico, o Memorial também desenvolve ações educativas por meio da oferta de cursos e palestras a educadores e grupos interessados. Desde o seu início, o Memorial também passou a inventariar os lugares públicos e privados de memória da resistência e da repressão políticas do estado por meio do Programa "Lugares da Memória", mas essa iniciativa ainda não deu resultados aparentes.

Em Buenos Aires, o ensino da temática está previsto para se estender desde o primeiro ciclo do nível primário até os últimos anos do nível médio. A ênfase está na incorporação da expressão "terrorismo de Estado" e na identificação do conceito de ditadura para dar conta das diversas interrupções da ordem democrática do país, nos chamados "gobiernos de facto". Os movimentos de resistência, armados ou não, têm nomes, líderes e bandeiras políticas, e a perspectiva regional se efetiva na abordagem detalhada das ditaduras em 
diferentes países da região, destacando a importância da colaboração entre os países no presente para revelar os documentos e os pontos de conexão entre essas histórias. A abordagem recorrente está voltada para a influência do passado no presente, com o reconhecimento dos lugares da cidade que simbolizam o período e a incorporação dos relatos de testemunho e álbuns de família na construção de narrativas sobre o passado, para estimular os estudantes a se sentirem parte dessa história.

Paralelamente, os calendários escolares também consolidaram o lugar das chamadas "efemérides de la memoria" de "conmemoración" obrigatória (González, 2012; Balestra, 2016). A primeira delas, o "16 de setiembre”, foi incorporada já em 1988, para lembrar um episódio conhecido como "La noche de los lápices”, um dos eventos repressivos contra o movimento estudantil secundarista, no qual dez estudantes do nível médio foram sequestrados e torturados na cidade de La Plata, em 1976. Seis dos estudantes não resistiram às torturas e até hoje se encontram desaparecidos. A partir de então, todos os anos, nessa mesma data, estudantes do nível médio de diversas instituições educativas realizam uma marcha por ruas de todo o país para recordar a "La Noche de los Lápices” e promover uma reflexão sobre a situação atual dos estudantes do nível médio.

Outra efeméride é o "24 de marzo", dia do golpe na Argentina, em 1976, que foi incorporado nos calendários escolares desde 1998, em nível nacional. Em 2002, o 24 de março foi instituído como "Día Nacional de la Memoria por la Verdad y la Justicia", solicitando-se que, nessa data, as escolas realizassem jornadas para consolidar a "memoria colectiva" e promover sentimentos que contestem toda forma de autoritarismo.

Não menos importante, o "10 de diciembre", dia em que assumiu o primeiro presidente democraticamente eleito do país, em 1983, também foi instituído como "Día Internacional de los Derechos Humanos" desde 2001, em dupla comemoração com a proclamação da Declaração Universal dos Direitos Humanos pelas Nações Unidas. Com isso, o Ministério da Educação Nacional determinou que todos os anos, na última semana do ano letivo, fosse realizada uma “Jornada de Reflexión Nacional sobre los Derechos Humanos” em todas as escolas da República Argentina.

Outros projetos ligados à educação patrimonial levam os estudantes a percorrerem a própria cidade para saberem que estão perto de lugares que 
serviram como prisões clandestinas - são os chamados "Sitios de Memoria del Terrorismo de Estado". Esses lugares passaram a ser sinalizados com placas externas, para que toda vez que alguém passasse por ali se lembrasse do que aconteceu no passado. Nessa mesma perspectiva, escolas públicas da cidade receberam placas com os nomes de professores e alunos mortos ou desaparecidos durante o período, que foram afixadas na porta das salas de aula que frequentavam.

Em 2001 foi inaugurado na cidade de Buenos Aires o "Parque de la Memoria", um monumento às vítimas da última ditadura e um centro de documentação sobre a vida e as circunstâncias de desaparecimento e/ou assassinato de cada uma das pessoas nomeadas no monumento. Em 2004, a "Escuela de Mecánica de la Armada" (ESMA) se transformou em "Espacio Memoria y Derechos Humanos" e passou a receber visitas guiadas de escolas e grupos (Balestra, 2016).

Além dessas iniciativas, também se consolidou na Argentina o Projeto "Jóvenes y Memoria", 9 que desde 2002 tem convocado escolas secundárias, tanto públicas como privadas, a se envolverem em um projeto anual sobre a última ditadura no país com uma premissa básica: que os próprios estudantes investiguem esse passado, com base em suas próprias perguntas e realidades locais. Com isso, elege-se um tema ou pergunta sobre algum aspecto dessa história em sua comunidade, e então equipes de estudantes e professores iniciam a investigação com metodologia análoga à que os historiadores utilizam, consultando arquivos, entrevistando pessoas e produzindo relatos nos quais expõem suas próprias conclusões, em diferentes suportes.

Nada semelhante, enquanto política pública de memória, se pode observar no Brasil. Ainda que o Memorial da Resistência de São Paulo tenha começado a dar os primeiros passos na elaboração de atividades educativas, as iniciativas que articulam os processos educativos à construção de memórias sobre a ditadura são incipientes diante da força do esquecimento promovido pelo silenciamento sobre esse passado no país.

A partir daí, é possível entender as diferenças nas narrativas produzidas pelos jovens de cada cidade. Em São Paulo, onde a história das ditaduras aparece apenas como mais um conteúdo a ser estudado, sem qualquer relação com o presente, grande parte dos jovens não se identifica com esse passado, e ele perde sua capacidade de orientar o presente. Parece que, em São Paulo, e talvez no 
restante do Brasil, como já indicaram alguns estudos, a reflexão sobre as ditaduras entre as novas gerações ainda não se tornou um problema, e seu desconhecimento permite todo tipo de manipulação. Já em Buenos Aires, onde "pasado reciente" foi assumido como eixo norteador das políticas públicas de memória, não só das escolas, mas da sociedade como um todo, o "deber de memoria" tem se estabelecido. Não só como memória literal, que remeteria apenas ao conhecimento do que se passou, mas como consciência histórica, servindo como princípio de ação para o presente e, em alguns casos, conferindo-lhe novos futuros.

É importante enfatizar que a Argentina não deve ser tomada como um modelo de referência. Recentemente, a abordagem dada às ditaduras nas escolas do país tem sido muito criticada pelos próprios argentinos, que agora se perguntam se constroem memórias ou se de fato ensinam história. Porque o "deber de memoria" assumido como eixo norteador do ensino e a ênfase na divulgação dos crimes cometidos pelo Estado terminaram por condicionar a realização de condenações automáticas e uma leitura moral e dualista do passado, que divide os sujeitos históricos em "buenos" e "malos" (Carnovale; Larramendy, 2010).

\section{PARA CONCLUIR}

Ainda que não se possa relacionar diretamente a dimensão curricular das políticas públicas de memória com as narrativas elaboradas pelos jovens que participaram da pesquisa - devendo-se considerar, também, o papel da mediação da escola, de seus professores, do meio familiar e dos meios de comunicação, dentre outros -, a forma como esse passado é assumido em cada cidade se refletiu na orientação de atitudes dos jovens que encerravam sua trajetória escolar em 2013, como parte de uma consciência histórica, conferindo ou negando perspectiva e historicidade às decisões tomadas no presente. Entender em detalhes como essa relação se processa no ensino de forma comparada demanda a realização de uma investigação intensiva sobre os processos de ensino e aprendizagem dessa história, mas alguns indícios já podem ser apontados:

\section{a) O alcance das propostas curriculares}

Em Buenos Aires, onde o ensino da temática está previsto desde o primeiro ciclo do nível primário até os últimos anos do nível médio, seja como 
diretriz curricular, seja por meio do trabalho com as efemérides, a relação estabelecida com a história das ditaduras e os detalhes oferecidos foram maiores. Além disso, também parece interferir a abordagem conceitual da ditadura, utilizada para caracterizar outros períodos da história argentina, o que pode ter contribuído para que alguns jovens desenvolvessem um sentimento de desconfiança para qualquer novo intento de restringir as liberdades democráticas, como o acesso a informação, proposto pela questão narrativa.

b) A relação do passado com o presente

É possível que os jovens de Buenos Aires tenham tido mais facilidade em relacionar o passado com o presente em suas narrativas porque essa é uma preocupação recorrente em todos os documentos curriculares da cidade e do país para a abordagem da temática: "recordar para no repetir", o que parece pautar todas as atividades desenvolvidas para o seu ensino. Em São Paulo, onde a história a ser ensinada sobre as ditaduras não envolve o estabelecimento de relações com o presente, nem sob a forma de construção de memórias, nem sob os reclamos por justiça e reparação, a maioria dos jovens pautou suas decisões apenas no presente, sem estabelecer qualquer relação com o contexto histórico apresentado no próprio instrumento.

\section{c) A interface com outras políticas públicas}

Em Buenos Aires, além das diretrizes curriculares para o ensino da temática, também se observa a institucionalização de outras políticas públicas para o seu ensino, sobretudo em âmbito nacional, ligados à educação patrimonial, à produção de materiais de apoio ao professor, à realização de jornadas de reflexão em épocas de comemoração de efemérides e ao apoio à realização de projetos, com a participação dos próprios alunos na construção de conhecimentos sobre o tema. Nem em São Paulo, nem no Brasil como um todo, existe algo semelhante.

\section{d) Abordagem regional da temática}

Como a questão proposta demarcava a relação entre países da região, tanto na partilha da história quanto no envolvimento dos personagens com a situação proposta, o entendimento dessas relações dependia do reconhecimento das conexões entre nosso passado e nosso presente. Nessa perspectiva, é possível que 
os alunos de Buenos Aires tenham tido mais facilidade em identificar e se posicionar frente a essas relações porque nas diretrizes curriculares e nos materiais didáticos que circulam na cidade a história das ditaduras é tratada a partir de uma abordagem regional, ao contrário de São Paulo, onde prevalece uma abordagem nacional do período, e isso repercute nas narrativas dos jovens investigados, mesmo que se destaque nas diretrizes a intenção de abordar o conteúdo de "ditadura militar" dentro de uma perspectiva regional.

e) Ênfase na participação civil ao longo do período

Parece haver uma relação entre a abordagem da participação civil durante o período, especialmente nos movimentos de resistência à ditadura, e o entendimento do próprio papel na defesa da democracia e dos direitos humanos entre os jovens que participaram da pesquisa, associado, por muitos, ao auxílio a um "perseguido político". Em Buenos Aires, onde os movimentos de resistência e de luta pelos direitos humanos, do passado e do presente, são abordados em detalhes, com nomes, lideranças, bandeiras e conquistas, o sentimento de responsabilidade não só com o "vizinho", mas também com a situação em que ele se encontrava, foi muito maior do que em São Paulo. Se os civis são vistos como atores sociais do período, individualmente ou a partir de movimentos organizados, o sentimento de corresponsabilidade pelos rumos que a história pode tomar no presente aumenta entre os jovens, fazendo que se posicionem em relação ao passado e ao futuro.

Esses indícios deixam claro que se pretendemos que o ensino de história promova o pensamento reflexivo entre os jovens, estimule que façam perguntas e que se questionem sobre suas próprias representações sobre o mundo e sobre si mesmos, então é necessário um novo tipo de ensino que abra espaço para o trabalho com suas próprias representações, seus imaginários, suas emoções, e não só o pretendido caráter neutro da ciência, que eles aceitam como tal, mas não incorporam às suas vidas (Montés, 2011). 


\section{REFERÊNCIAS}

BALESTRA, Juliana P. C. Entre muitos 'outros': ensino de história e integração latino-americana. Revista Historia e Diversidade, Cáceres, v.7, n.2, p.7-23, 2015a.

. História e Ensino de História das Ditaduras no Brasil e na Argentina. Revista Antiteses, Londrina, v.9, n.18, p.249-274, jul./dez. 2016.

O peso do passado: currículos e narrativas no ensino de História das Ditaduras de Segurança Nacional em São Paulo e Buenos Aires. Tese (Doutorado em Educação) - Faculdade de Educação, Universidade Estadual de Campinas (Unicamp). Campinas, 2015.

BAUER, Caroline S. Um estudo comparativo das práticas de desaparecimento nas ditaduras civil-militares argentina e brasileira e a elaboração de políticas de memória em ambos os países. Tese (Doutorado em História) - Programa de Pós-graduação em História, Universidade Federal do Rio Grande do Sul; Departament d'Història Contemporània, Universitat de Barcelona. Porto Alegre e Barcelona, 2011.

. A intervenção militar de hoje e de ontem. Carta Maior, 16 mar. 2015. Disponível em: http://cartamaior.com.br/?/Editoria/Direitos-Humanos/Aintervencao-militar-de-hoje-e-de-ontem/5/33066; acesso em: 5 set. 2015.

CARNOVALE, Vera; LARRAMENDY, Alina. Enseñar la historia reciente en la escuela: problemas y aportes para su abordaje. In: SIEDE, Isabelino A. (Coord.) Ciencias sociales en la escuela. Buenos Aires: Aique, 2010.

CERRI, Luis Fernando (Org.) O ensino de história e a ditadura militar. 2.ed. Curitiba: Aos Quatro Ventos, 2003.

FRANCO, Marina; LEVÍN, Florencia. El pasado cercano en clave historiográfica. In: FRANCO, Marina; LEVÍN, Florencia (Comp.) Historia reciente: perspectivas y desafíos para un campo en construcción. Buenos Aires: Paidós, 2007.

GONZÁLEZ, María Paula. Historia y memoria del pasado reciente en la escuela: una mirada a la propuesta oficial. Revista Quinto Sol, v.16, n.2, p.1-24, jul./dic. 2012.

KOSELLECK, Reinhart. Futuro passado: contribuição à semântica dos tempos históricos. Rio de Janeiro: Contraponto; Ed. PUC-Rio, 2006.

MENDES, Ricardo A. S. Ditaduras civil-militares no Cone Sul e a Doutrina de Segurança Nacional - algumas considerações sobre a Historiografia. Revista Tempo e Argumento, Florianópolis, v.5, n.10, p.6-38, jul./dez. 2013.

MONTÉS, Rafael V. La multiculturalidad en la enseñanza de la Historia y el desajuste entre intenciones educativas y prácticas escolares: los retos del presente y del futuro inmediato. Educar em Revista, Curitiba, n.42, p.73-94, out. 2011.

RÜSEN, Jörn. Como dar sentido ao passado: questões relevantes de meta-história. Revista História da Historiografia, Ouro Preto, n.2, p.163-209, mar. 2009. 
RÜSEN, Jörn. Cultura faz sentido: orientações entre o ontem e o amanhã. Petrópolis: Vozes, 2014.

. El desarrollo de la competencia narrativa en el aprendizaje histórico: una hipótesis ontogenética relativa a la conciencia moral. Revista Propuesta Educativa, Buenos Aires, v.4, n.7, p.27-36, oct. 1992.

SADER, Emir; JINKINGS, Ivana; MARTINS, Carlos Eduardo; NOBILE, Rodrigo (Coord.) Latinoamericana: enciclopédia contemporânea da América Latina e do Caribe. São Paulo: Boitempo, 2006.

SARLO, Beatriz. Tempo passado: cultura da memória e guinada subjetiva. São Paulo: Companhia das Letras, 2007.

\section{NOTAS}

${ }^{1}$ A chamada "Doutrina de Segurança Nacional" tem suas raízes nos Estados Unidos, fora do solo latino-americano, envolvida pelo contexto da Guerra Fria, quando Estados Unidos e União Soviética disputavam a hegemonia política, econômica e militar ao redor do mundo após a Segunda Guerra Mundial. Entre os seus antecedentes está o reconhecimento de que, em uma guerra, as batalhas não ocorrem apenas no front militar, mas também nos campos cultural, econômico e social, na disputa por corações e mentes. Entre as décadas de 1960 e 1980, boa parte dos oficiais militares da América Latina entraram em contato com essa Doutrina por meio da "Escola das Américas", um instituto do Departamento de Defesa dos Estados Unidos, à época situado no Panamá, onde eram instruídos a levar a cabo a guerra interna contra o comunismo e a responder aos interesses vitais de suas nações: segurança e desenvolvimento (Cf. MENDES, 2013).

${ }^{2}$ Cf. Matéria do jornal O Globo (por Tatiana Farah, 30 mar. 2014). Disponível em: http:// oglobo.globo.com/brasil/marcha-que-festeja-50-anos-do-golpe-reune-150-pessoas-na-paulista-120368 19\#ixzz3SIWi3Vxu; acesso em: 15 nov. 2014.

${ }^{3}$ Descrição do perfil da comunidade "Volta Ditadura" na rede social Facebook, com milhares de seguidores. Disponível em: https://www.facebook.com/voltaditadura; acesso em: 5 set. 2015.

${ }^{4}$ A pesquisa completa foi apresentada em 2015 ao Programa de Pós-Graduação em Educação da Unicamp sob a forma de Tese de Doutorado, orientada pela profa. dra. Ernesta Zamboni (BALESTRA, 2015). A descrição dos instrumentos de pesquisa e os dados relativos à cidade de São Paulo, em sua especificidade, foram publicados anteriormente (BALESTRA, 2015a), tomando-se como problemática central as relações com os imigrantes latino-americanos nas escolas de São Paulo.

${ }^{5}$ A questão foi elaborada com base em um modelo produzido por Jörn Rüsen para investigar os diferentes tipos de consciência histórica (RÜSEN, 1992). 
${ }^{6}$ Os instrumentos foram aplicados pelos professores de cada turma, no horário de suas aulas, deixando claro que a participação no estudo era totalmente voluntária. Para a manutenção do sigilo sobre a identidade dos estudantes e de seus professores, o nome das escolas não será divulgado. É importante salientar que o número de escolas participantes de nenhum modo pretende ser representativo do que acontece com a formação histórica em cada uma das duas cidades e tem como fim apenas ilustrar as tendências gerais em um universo tomado como referência.

${ }^{7}$ A análise detalhada da dimensão nacional das políticas públicas de memória e ensino de história das ditaduras no Brasil e na Argentina pode ser conferida em BALESTRA, 2016.

${ }^{8}$ Em Fortaleza, o coletivo "Aparecidos Políticos" realiza intervenções urbanas e mapeou os lugares que homenageiam ditadores, torturadores e apoiadores da ditadura. Em Recife, o livro Recife Lugar de Memória apresenta rotas temáticas que revisitam locais da cidade em diferentes períodos históricos, entre eles o da ditadura. Em Porto Alegre, as marcas do autoritarismo e da luta pela democracia estão em um panfleto on-line que localiza 40 lugares que funcionaram como centros de detenção e tortura ou se tornaram símbolos da resistência da cidade.

${ }^{9}$ Disponível em: http://jovenesymemoria.comisionporlamemoria.net; acesso em: 10 abr. 2015.

Artigo recebido em 8 de janeiro de 2018. Aprovado em 27 de agosto de 2018. 